\title{
Skrining Kanker Payudara pada Wanita di Indonesia
}

\section{Breast Cancer Screening among Indonesian Women}

\author{
Solikhah Solikhah ${ }^{{ }^{*}}$ \\ ${ }^{1 *}$ Fakultas Kesehatan Masyarakat, Universitas Ahmad Dahlan, Yogyakarta, Indonesia. \\ (solikhah@ikm.uad.ac.id)
}

\begin{abstract}
ABSTRAK
Kanker payudara masih menjadi masalah kesehatan masyarakat di dunia dan menjadi penyebab kematian utama di kalangan wanita. Skrining kanker payudara dikenal sebagai metode untuk menurunkan kematian pasien kanker payudara, namun banyak faktor yang menghambat seseorang untuk melakukan skrining kanker payudara. Penelitian ini bertujuan mengeksplorasi skrining kanker payudara pada wanita di Indonesia. Sampel diambil secara statifikasi acak bertingkat pada sebanyak 864 wanita yang berumur $\geq 18$ tahun di tiga lokasi yaitu: Yogyakarta, Sumatera Selatan dan Nusa Tenggara Timur. Multinomial logistic regression digunakan untuk menganalisis semua item dari kuesioner terhadap skrining kanker payudara. Dari 864 responden wanita, sebagian besar berumur $\geq 50$ tahun (7,52\%). Selain itu, responden yang melakukan mammografi atau Clinical Breast Screening (CBE) hanya $18,29 \%$. Umur wanita $\geq 50$ tahun memiliki tingkat kesadaran lebih rendah untuk tidak melakukan skrining sebesar 3,07 kali dibandingkan dengan wanita berumur $<50$ tahun, tetapi umur pada wanita yang melakukan CBE atau Mammography tidak menunjukkan signifikansi. Tingkat pendidikan, agama, status pernikahan, dan kepemilikan asuransi kesehatan secara signifikan berpengaruh pada skrining kanker payudara.
\end{abstract}

Kata kunci : Skrining kanker payudara, mammography, wanita Indonesia

\begin{abstract}
Breast cancer is a public health problem worldwide and a major cause of death among women. Breast cancer screening is well known as a method to reduce breast cancer death, while, several barriers to breast cancer screening were identified. This study aimed to explore breast cancer screening among Indonesian women. Samples were taken by stratified random sampling in 864 women aged $\geq 18$ in three places, namely: Yogyakarta, South of Sumatera, and East Nusa Tenggara. Multinomial logistic regression was used to analyse all items of the questionnaire against breast cancer screening. Of 864 females, the majority were aged $\geq 50$ years (7.52\%). In addition, respondents who performed clinical breast examination (CBE) or mammography were 18.29\%. Women's age $\geq 50$ years hadthe odds lower level of awareness forno perform breast cancer screening 3.07times higher compared to women aged $<50$ years, but women's age who did CBE or Mammography did not show significance. Education, religion, marital status, and health insurance are significantly associated with breast cancer screening. Keywords : Breast cancer screening, mammography, Indonesian women
\end{abstract}




\section{PENDAHULUAN}

Kanker masih menjadi masalah kesehatan masyarakat di seluruh dunia, dikarenakan banyaknya kesakitan dan kematian akibat kanker. Berdasarkan data GLOBOCAN terdapat 2,1 juta kasus baru penderita kanker. ${ }^{1}$ Selain itu kanker payudara dilaporkan menjadi penyebab kematian utama pada kelompok wanita baik di negara maju maupun negara berkembang. ${ }^{2}$ Di Indonesia dilaporkan bahwa kanker payudara mayoritas ditemukan pada kelompok wanita, meskipun angka insidensi kanker payudara ini menduduki peringkat kedua di antara negara-negara Asia. ${ }^{3}$

Peningkatan angka kejadian kanker payudara terutama di negara-negara berkembang dikarenakan adanya perubahan gaya hidup diantaranya : rendahnya partisipasi masyarakat dalam berolahraga, peningkatan jumlah orang yang mengalami obesitas, dan konsumsi alkohol. ${ }^{1}$ Selain itu, sebagian besar penderita saat didiagnosis kanker payudara sudah dalam stadium lanjut. ${ }^{4}$ Angka kematian penderita kanker payudara di negara maju lebih rendah dibandingkan dengan negara berkembang. Hal ini dikarenakan, penemuan penderita kanker payudara lebih awal memberi peluang besar kepada pasien untuk mendapatkan pengobatan lebih dini. ${ }^{5}$

Beberapa program untuk mengurangi faktor risiko kanker payudara telah dilakukan. Skrining atau penemuan penderita secara dini dapat meningkatkan keberlangsungan hidup penderita kanker payudara. ${ }^{6,7}$ Mammography adalah satu-satunya skrining yang direkomendasikan oleh World Health Organization (WHO), namun penemuan penderita secara massal dengan menggunakan metode skrining ini sangat sulit dilakukan terutama di negara berkembang termasuk di Indonesia. Biaya yang relatif tinggi untuk melakukan Mammography diidentifikasi sebagai faktor utama tidak dilakukannya skrining kanker payudara secara masal. Pemberdayaan masyarakat melalui kesadaran masyarakat untuk mengenali lebih dini gejala dan tanda kanker payudara menggunakan metode Breast Self Examination (BSE) serta Clinical Breast Examination sangat tepat sebagai upaya penemuan dini penderita kanker payudara terutama di negara-negara berkembang seperti halnya di Indonesia. ${ }^{89}$ Khusus di Indonesia, belum adanya program skrining rutin dari pe- merintah dikarenakan lemahnya tenaga kesehatan dan infrastruktur pelayanan kesehatan juga memicu tingginya tingkat kesakitan dan kematian kanker payudara, disamping kesadaran masyarakat mengenali tanda dan gejala awal kanker payudara masih rendah. Berdasarkan latar belakang tersebut diatas perlu dilakukan eksplorasi skrining kanker payudara di Indonesia untuk membantu pemerintah dalam upaya memperpanjang keberlangsungan hidup penderita serta menurunkan kematian kanker payudara.

\section{BAHAN DAN METODE}

Rancangan cross sectional digunakan dalam melakukan penelitian ini. Sampel diambil secara statifikasi acak bertingkat pada sebanyak 864 wanita yang berumur $\geq 18$ tahun, yang diambil dari tiga lokasi yaitu: Yogyakarta, Sumatera Selatan dan Nusa Tenggara Timur. Pemilihan ketiga lokasi tersebut untuk mewakili provinsi dengan tingkat insidensi kanker payudara tinggi, menengah dan rendah. ${ }^{10}$ Wawancara kepada responden dilakukan pada bulan Maret sampai dengan Mei 2016 dengan kriteria responden tidak sedang menderita kanker payudara, tidak sedang hamil, tidak sedang menyusui, memahami Bahasa Indonesia dan bersedia ikut berpartisipasi dalam penelitian ini. Protokol penelitian ini telah disetujui oleh komite etik dari Khon Kaen University, Thailand dengan nomor (HE582369).

Instrumen dalam penelitian ini menggunakan kuesioner yang telah tervalidasi, dengan nilai Cronbach's Alpha sebesar 0,79. ${ }^{11}$ Kuesioner berisi tentang tingkat pengetahuan risiko kanker payudara dan karekterikstik responden. Sementara variabel dependen adalah skrining kanker payudara, yang berskala polikotomi (tingkat skinning, BSE, CBE atau Mammography). Tingkat pengeTahuan kanker payudara diukur menggunakan skala respon kategori (Ya, Tidak dan Tidak tahu). Untuk karekaterisktik sampel terdapat 8 pertanyaan yaitu umur, wilayah, tingkat pendidikan, status pernikahan, agama, pendapatan perbulan, pekerjaan, kepemilikan asuransi kesehatan serta riwayat merokok.

Analisis deskriptif digunakan untuk meringkas data dari sampel penelitian. Distribusi frekwensi dan presentase digunakan untuk mengukur data yang berskala kategori, semen- 
tara data yang berskala kontinyu diukur dengan nilai rata-rata \pm standar deviasi (SD). Multinomial logistic regression digunakan untuk menganalisis semua item dari kuesioner terhadap skrining kanker payudara. Seluruh analisis data menggunakan program STATA versi 13.0.

\section{HASIL}

Dari 864 wanita Indonesia yang bersedia dan berpartisipasi dalam penelitian ini, sebagian besar berumur $\geq 50$ tahun $(7,52 \%)$ dan berpenghasilan dibawah Rp. 200.000,00 per bulan $(75,58 \%)$. Selain itu responden yang melakukan pemeriksaan payudara sendiri (breast seft examination/BSE) sekitar $47,34 \%$ dan yang melakukan skrining dengan mammografi atau CBE hanya $18,29 \%$. Informasi lebih rinci tenang karakteristik responden dalam penelitian ini disajikan di Tabel 1.

Tabel 2 menjelaskan tentang nilai analisis uji statistik Multinomial logistic regression model untuk skrining kanker payudara pada wanita di Indonesia. Berdasarkan pada Tabel 2, dapat diketahui bahwa umur $\geq 50$ tahun memiliki tingkat kesadaran lebih rendah tidak melakukan skrining sebesar 3,07 kali lebih rendah dibandingkan dengan wanita berumur $<50$ tahun (AOR:3,07; 95\% CI: $1,96-4,81 ; \mathrm{p}<0,001)$, tetapi umur pada wanita yang melakukan $\mathrm{CBE}$ atau Mammography tidak menunjukkan signifikansi. Selain umur, wanita beragama non Muslim (AOR: 0,25; 95\%CI: $0,149-0,44 ; \mathrm{p}<0,001)$ dan wanita berpendidikan tinggi (AOR: 0,21; 95\%CI: 0,10-0,46; $\mathrm{p}<0,001)$ berhubungan secara signifikan untuk tidak melakukan skrining kanker payudara. Wanita yang sudah menikah mempunyai risiko 1,92 kali lebih tinggi dibandingkan dengan wanita yang belum menikah untuk tidak melakukan skrining kanker payudara (AOR: 1,92; 95\% CI: $1,20-3,08 ; p<0,01)$. Wanita yang sudah menikah tersebut juga berkontribusi menurunkan $61 \%$ untuk melakukan CBE atau Mammography (AOR: 0,39; 95\%CI: $0,21-0,72 ; \mathrm{p}<0,01)$. Kepemilikan asuransi (AOR: 0,02; 95\% CI: 0,01-0,04; $<<0,001$ ) dan pendapatan perbulan $\geq \mathrm{Rp} 2.000 .000,00$ (AOR: 0,$09 ; 95 \%$ CI: $0,03-0,33 ; \mathrm{p}<0,001$ ) juga mempunyai hubungan bermakna dengan wanita untuk melakukan CBE atau Mammography.
Tabel 1. Karakteristik Responden pada Skrining Kanker Payudara di Indonesia $(n=864)$

\begin{tabular}{|c|c|}
\hline Karakteristik & $\mathbf{n}(\%)$ \\
\hline \multicolumn{2}{|l|}{ Umur } \\
\hline Pra dewasa $(<50$ tahun $)$ & $799(92,48)$ \\
\hline Dewasa ( $\geq 50$ tahun) & $65(7,52)$ \\
\hline \multicolumn{2}{|l|}{ Wilayah } \\
\hline Desa & $536(62.04)$ \\
\hline Kota & $328(37.96)$ \\
\hline \multicolumn{2}{|l|}{ Agama } \\
\hline Muslim & $589(68,17)$ \\
\hline Protestan & $48(5,56)$ \\
\hline Lainnya & $227(26,27)$ \\
\hline \multicolumn{2}{|l|}{ Tingkat Pendidikan } \\
\hline Tamat SD & $66(7,64)$ \\
\hline Tamat SLTP & $60(6,94)$ \\
\hline Tamat SLTA & $329(38,08)$ \\
\hline Pendidikan tinggi & $409(47,34)$ \\
\hline \multicolumn{2}{|l|}{ Status Pernikahan } \\
\hline Belum Menikah & $428(49,54)$ \\
\hline Menikah/Cerai/Berpisah & $436(50,46)$ \\
\hline \multicolumn{2}{|l|}{ Pekerjaan } \\
\hline Tidak Bekerja & $47(5.44)$ \\
\hline Petani & $85(9.84)$ \\
\hline Pedagang & $68(7.87)$ \\
\hline Pekerja Buruh & $201(23.26)$ \\
\hline PNS/Pegawai/Pengusaha & $463(53.59)$ \\
\hline \multicolumn{2}{|l|}{ Pendapatan } \\
\hline Rp. $<2.000 .000,00$ & $653(75,58)$ \\
\hline Rp. $\geq 2.000 .000,00$ & $211(24,42)$ \\
\hline \multicolumn{2}{|l|}{ Keikutsertaan Asuransi Kesehatan } \\
\hline $\mathrm{Ya}$ & $522(60,42)$ \\
\hline Tidak & $342(39,58)$ \\
\hline \multicolumn{2}{|l|}{ Riwayat Merokok } \\
\hline $\mathrm{Ya}$ & $18(2,08)$ \\
\hline Tidak & $846(97,92)$ \\
\hline \multicolumn{2}{|l|}{$\begin{array}{l}\text { Tingkat pengetahuan risiko kanker } \\
\text { payudara }\end{array}$} \\
\hline Rendah & $155(17,94)$ \\
\hline Sedang & $566(65,51)$ \\
\hline Baik & $143(16,55)$ \\
\hline \multicolumn{2}{|l|}{ Skrining kanker payudara } \\
\hline Tidak pernah skrining & $297(34,38)$ \\
\hline Breast self examination (BSE) & $409(47,34)$ \\
\hline $\begin{array}{l}\text { Clinical breast screening (CBE) } \\
\text { atau Mammography }\end{array}$ & $158(18,29)$ \\
\hline
\end{tabular}

\section{PEMBAHASAN}

Skrining kanker payudara telah dikenal sebagai metode untuk mengurangi jumlah kematian karena kanker payudara. ${ }^{12,13}$ Namun skrining massal menggunakan CBE dan Mammography 
Tabel 2. Multinomial Logistik Regresi pada Skrining Kanker Payudara di Indonesia

\begin{tabular}{|c|c|c|c|c|c|c|c|c|}
\hline \multirow{2}{*}{ Variabel } & \multicolumn{4}{|c|}{ Tidak Pernah Screening } & \multicolumn{4}{|c|}{ CBE/ Mammography } \\
\hline & OR & $95 \% \mathrm{CI}$ & AOR & $95 \% \mathrm{CI}$ & OR & $95 \% \mathrm{CI}$ & AOR & $95 \% \mathrm{CI}$ \\
\hline \multicolumn{9}{|l|}{$\begin{array}{l}\text { Tingkat pengetahuan } \\
\text { risiko kanker payudara }\end{array}$} \\
\hline Sedang & 0,92 & $0,61-1,38$ & 0,73 & $0,44-1,21$ & $0,57^{*}$ & $0,36-0,91$ & 0,59 & $0,31-1,12$ \\
\hline Baik & 0,63 & $0,37-1,07$ & 0,75 & $0,37-1,47$ & 0,65 & $0,36-1,17$ & 0,50 & $0,22-1,13$ \\
\hline Umur & 7,63 & $5,36-10,85$ & $3,07^{* * *}$ & $1,96-4,81$ & 0,44 & $0,23-0,85$ & 0,49 & $0,21-1,10$ \\
\hline Wilayah & 0,79 & $0,58-1,07$ & 0,61 & $0,41-0,91$ & $0,61^{*}$ & $0,41-0,89$ & 1,13 & $0,63-2,04$ \\
\hline Agama & & & & & & & 1,33 & $0,97-1,83$ \\
\hline Protestan & $0,44^{* *}$ & $0,22-0,88$ & 0,42 & $0,19-0,94$ & 0,77 & $0,34-1,75$ & 1,39 & $0,42-4,61$ \\
\hline Lainnya & $0,16^{* * *}$ & $0,10-0,25$ & $0,25^{* * *}$ & $0,14-0,44$ & 1,04 & $0,71-1,54$ & 1,77 & $0,93-3,35$ \\
\hline \multicolumn{9}{|l|}{ Tingkat pendidikan } \\
\hline Tamat SLTP & 0,55 & $0,23-1,31$ & 0,54 & $0,21-1,37$ & 1,2 & $0,31-4,61$ & 0,71 & $0,16-3,18$ \\
\hline Tamat SLTA & $0,12^{* * *}$ & $0,06-0,23$ & $0,21^{* * *}$ & $0,99-0,45$ & 1,16 & $0,39-3,40$ & 0,62 & $0,18-2,19$ \\
\hline Pendidikan tinggi & $0,15^{* * *}$ & $0,08-0,30$ & $0,21^{* * *}$ & $0,10-0,46$ & 0,72 & $0,25-2,12$ & 0,35 & $0,10-1,26$ \\
\hline Status pernikahan & $7,89^{* * *}$ & $5,50-11,30$ & $1,92^{* *}$ & $1,20-3,08$ & $0,53^{* *}$ & $0,35-0,80$ & $0,39^{* *}$ & $0,21-0,72$ \\
\hline $\begin{array}{l}\text { Keikutsertaan asuransi } \\
\text { kesehatan }\end{array}$ & 0,78 & $0,56-1,09$ & 0,97 & $0,64-1,46$ & $0,03^{* * *}$ & $0,02-0,05$ & $0,02^{* * *}$ & $0,01-0,04$ \\
\hline Pendapatan & $4,20^{* * *}$ & $2,98-5,93$ & $4,63^{* * *}$ & $2,98-7,19$ & $0,09^{* * *}$ & $0,03-0,30$ & $0,09^{* * *}$ & $0,03-0,33$ \\
\hline
\end{tabular}

Keterangan: $\mathrm{AOR}=$ Adjusted Odds Ratio $; \mathrm{OR}=$ Odds Ratio $; \mathrm{CI}=$ Confidence Interval .

$$
{ }^{* * *}=\mathrm{p}<0,001,{ }^{* *}=\mathrm{p}<0,01,{ }^{*}=\mathrm{p}<0,05
$$

belum dapat diterapkan di negara-negara berkembang seperti halnya di Indonesia, dikarenakan keterbatasan infrastruktur dan sumber daya di pelayanan kesehatan. ${ }^{14}$ Program Mammography secara massal saat ini hanya dapat diterapkan di negara maju yang memiliki fasilitas pelayanan kesehatan dengan infrastruktur yang baik. ${ }^{15,16,17}$

Upaya untuk meningkatkan kesadaran dan pengetahuan masyarakat kaitannya dengan tanda dan gejala awal dari kanker payudara sangat diperlukan. Hal ini dimaksudkan agar masyarakat lebih dini dapat mengenali gejala kanker payudara, sehingga bersegera untuk mencari pengobatan di pelayanan kesehatan. Tingkat kesadaran dan pengetahuan yang rendah tentang tanda dan gejala dini kanker payudara secara signifikan berhubungan dengan banyaknya pasien di diagnosis kanker payudara stadium lanjut, saat mereka pertama kali diperiksa oleh tenaga medis. ${ }^{18,19}$

Berdasarkan hasil penelitian didapatkan data bahwa umur $\geq 50$ tahun secara signifikan memberikan kontribusi pada wanita untuk tidak melakukan skrining kanker payudara. Tingkat pengetahuan dan kesadaran yang rendah menyebabkan penderita kanker payudara menjadi enggan untuk tidak melakukan skrining kanker payuda- ra. Umur antara 50-74 tahun, saat yang tepat untuk melakukan skrining kanker payudara, dan dari penelitian menyebutkan bahwa umur 50-75 sangat direkomendasikan untuk menurunkan angka kematian kanker payudara. ${ }^{20}$ Selain itu, wanita yang tinggal di perkotaan cenderung secara nyata tidak melakukan skrining kanker payudara sekitar 39\% dibandingkan dengan wanita yang tinggal di pedasaan. Aktivitas dan kesibukan yang lebih komplek di perkotaan menjadikan wanita tersebut enggan untuk tidak melakukan skrining kanker payudara. Selain itu biaya yang mahal menjadi salah satu alasan untuk tidak melakukan skrining kanker payudara. ${ }^{21}$ Disamping hal tersebut sebelumnya, faktor sosial ekonomi wanita Indonesia, seperti tingkat pendidikan, kepemilikan asuransi kesehatan, tingkat pendapatan, agama, menjadi kontributoryang signifikan mempengaruhi skrining kanker payudara. Beberapa penelitian di negara berkembang melaporkan bahwa faktor sosial ekonomi menjadi penghambat bagi seseorang untuk melakukan skrining kanker payudara. Selain biaya, kemudahan akses ke tempat fasilitas rumah sakit, tingkat kesadaran dan pengetahuan tentang pentingnya skrining kanker, dan ketakutan di diagnosis kanker menjadi penghambat seseorang enggan melakukan skrining kanker. ${ }^{21,22}$ 
Ketakutan wanita ditinggalkan oleh pasangan hidup atau suami juga menjadi faktor penting bagi seorang wanita saat akan menjalani pemeriksaan ke pelayanan kesehatan. Hal ini terlihat dari penelitian yang telah dilakukan di negara yang mayoritas Muslim seperti di Indonesia melaporkan bahwa wanita enggan untuk dilakukan masektomi jika di diagnosis kanker payudara, dikarenakan takut ditinggalkn oleh pasangan hidup. ${ }^{23,24}$ Selain itu, wanita yang bersuami sangat bergantung pada nafkah yang diberikan oleh suami. ${ }^{25}$ Dari hasil penelitian menunjukkan bahwa mammography atau CBE pada wanita yang belum menikah atau yang cerai turun sekitar $61 \%$. Peningkatan kesadaran dan pengetahuan gejala awal kanker payudara dan manfaat skrining kanker lebih awal sangat dibutuhkan untuk memperpanjang kualitas hidup pasien. ${ }^{26}$

Penelitian ini memiliki beberapa kekuatan seperti kuesioner yang digunakan dalam penelitian ini menggunakan kuesioner yang sudah tervalidasi. ${ }^{11}$ Selain itu, tanggapan responden dalam penelitian ini diatas $90 \%$ dan diambil dari sampel yang besar yaitu sebanyak 864 wanita yang tersebar di tiga propinsi. Ketiga propinsi tersebut mewakili tingkat insidensi penderita kanker di Indonesia dan menggambarkan konteks keberagaman seperti: wilayah, budaya dan agama. Meskipun demikian, di penelitian ini juga terdapat keterbatasan, yaitu: desain penelitian ini menggunakan rancangan cross-Sectional, dimana variabel-variabel seperti tingkat pendapatan, tingkat pendidikan didapatkan langsung dari responden tanpa validasi eksternal, yang memungkinkan bias akurasi data dapat terjadi selama penelitian.

\section{KESIMPULAN DAN SARAN}

Faktor sosial ekonomi wanita seperti umur, domisili tempat tinggal, agama, tingkat pendidikan, status pernikahan, kepemilikan asuransi kesehatan, dan tingkat pendapatan secara signifikan berhubungan dengan skrining kanker payudara. Diperlukan upaya peningkatan pengetahuan dan kesadaran ke seluruh masyarakat pentingnya skrining kanker payudara untuk meningkatkan kualitas hidup pasien kanker oleh pemerintah dan dinas kesehatan terkait.

\section{UCAPAN TERIMA KASIH}

Terimakasih diucapkan kepada ACEP Research Group, Faculty of Public Health, Khon Kaen University, Thailand yang telah membantu dalam pembiayaan penelitian ini.

\section{DAFTAR PUSTAKA}

1. Bray F, Ferlay J, Soerjomataram I, Siegel RL, Torre LA, Jemal A. Global Cancer Statistics 2018: GLOBOCAN estimates of incidence and Mortality Worldwide for 36 Cancers in 185 Countries. CA Cancer J Clin. 2018 Sep 12;68(6):394-424.

2. Ghoncheh M, Pournamdar Z, Salehiniya H. Incidence and Mortality and Epidemiology of Breast Cancer in the World. Asian Pac J Cancer Prev. 2016;17(S3):43-6.

3. Youlden DR, Cramb SM, Yip CH, Baade PD. Incidence and Mortality of Female Breast Cancer in the Asia-Pacific Region. Cancer Biol Med. 2014;11(2):101-15.

4. Hossain MS, Ferdous S, Karim-Kos HE. Breast Cancer in South Asia: a Bangladeshi Perspective. Cancer Epidemiol. 2014;38(5):465-70.

5. Oeffinger KC, Fontham ETH, Etzioni R, Herzig A, Michaelson JS, Shih Y-CT, et al. Breast Cancer Screening for Women at Average Risk: 2015 Guideline Update From the American Cancer Society. JAMA. 2015;314(15):1599614.

6. Saadatmand S, Bretveld R, Siesling S, Tilanus-Linthorst MMA. Influence of Tumour Stage at Breast Cancer Detection on Survival in Modern Times: Population Based Study in 173797 Patients. BMJ. 2015;351:h4901.

7. Fei X, Wu J, Kong Z, Christakos G. Urban-Rural Disparity of Breast Cancer and Socioeconomic Risk Factors in China. PloS One. 2015;10(2): 0117572.

8. El Saghir NS, Adebamowo CA, Anderson BO, Carlson RW, Bird PA, Corbex M, et al. Breast Cancer Management in Low Resource Countries (LRCs): Consensus Statement from the Breast Health Global Initiative. The Breast. 2011;20 Suppl 2:S3-11.

9. Hossain MS, Ferdous S, Karim-Kos HE. Breast Cancer in South Asia: A Bangladeshi Perspective. Cancer Epidemiol. 2014;38(5):465-70.

10. Kementerian Kesehatan RI. Situasi Penyakit 
kanker. Pusat Data dan Informasi, Kementerian Kesehatan RI; 2015.

11. Solikhah S, Promthet S, Rakkapao N, Hurst CP. Validation of an Indonesian Version of the Breast Cancer Awareness Scale (BCAS-I). Asian Pac J Cancer Prev. 2017;18(2):515-22.

12. Nelson HD, Fu R, Cantor A, Pappas M, Daeges M, Humphrey L. Effectiveness of Breast Cancer Screening: Systematic Review and Meta-analysis to Update the 2009 U.S. Preventive Services Task Force Recommendation. Ann Intern Med. 2016;164(4):244-55.

13. Lauby-Secretan B, Loomis D, Straif K. Breast Cancer Screening Viewpoint of the IARC Working Group. N Engl J Med. 2015;372(24):2353-8.

14. Li J, Shao Z. Mammography Screening in Less Developed Countries. SpringerPlus. 2015;4(615):2-15.

15. Nelson HD, Fu R, Cantor A, Pappas M, Daeges M, Humphrey L. Effectiveness of Breast Cancer Screening: Systematic Review and Meta-analysis to Update the 2009 U.S. Preventive Services Task Force Recommendation. Ann Intern Med. 2016;164(4):244-55.

16. Welch HG, Prorok PC, O'Malley AJ, Kramer BS. Breast-Cancer Tumor Size, Overdiagnosis, and Mammography Screening Effectiveness. N Engl J Med. 2016;375(15):1438-47.

17. Løberg M, Lousdal ML, Bretthauer M, Kalager M. Benefits and Harms of Mammography Screening. Breast Cancer Res. 2015;17(1):63.

18. Mills A. Health Care Systems in Low and Middle-Income Countries. N Engl J Med. 2014;370(6):552-7.

19. Ramathuba DU, Ratshirumbi CT, Mashamba TM. Knowledge, Attitudes and Practices toward Breast Cancer Screening in a Ru- ral South African Community. Curationis. 2015;38(1):1172.

20. Braithwaite D, Demb J, Henderson LM. Optimal Breast Cancer Screening Strategies for Older Women: Current Perspectives. Clin Interv Aging. 2016 Feb 3;11:111-25.

21. Patel K, Kanu M, Liu J, Bond B, Brown E, Williams E, et al. Factors Influencing Breast Cancer Screening in Low-Income African Americans in Tennessee. J Community Health. 2014 Oct;39(5):943-50.

22. Chor JSY, Lam HCY, Chan A, Lee HM, Fok E, Griffiths S, et al. Socioeconomic Disparity in Breast Cancer Detection in Hong Kong A High Income City: Retrospective Epidemiological Study Using the Breast Cancer Registry. PLOS ONE. 2014 Oct 1;9(10):e107630.

23. Kawar LN. Barriers to Breast Cancer Screening Participation among Jordanian and Palestinian American women. Eur J Oncol Nurs. 2013 Feb 1;17(1):88-94.

24. Ferrat E, Le Breton J, Djassibel M, Veerabudun $\mathrm{K}$, Brixi Z, Attali $\mathrm{C}$, et al. Understanding Barriers to Organized Breast Cancer Screening in France: Women's Perceptions, Attitudes, and Knowledge. Fam Pract. 2013 Aug;30(4):445-51.

25. Donnelly TT, Khater A-HA, Kuwari MGA, Al-Bader SB, Al-Meer N, Abdulmalik M, et al. Do Socioeconomic Factors Influence Breast Cancer Screening Practices among Arab Women in Qatar? BMJ Open. 2015;5(1):e005596.

26. Elobaid YE, Aw TC, Grivna M, Nagelkerke N. Breast Cancer Screening Awareness, Knowledge, and Practice among Arab Women in the United Arab Emirates: A Cross-Sectional Survey. PLOS ONE. 2014 Sep 29;9(9):e105783. 